\title{
Situating Learning for Digital Inclusion in the Social Context of Communities
}

\author{
Fabio N. Akhras
}

Centro de Tecnologia da Informação Renato Archer

\begin{abstract}
An approach to support learning for digital inclusion has been developed which situates learning for digital inclusion in the social context of communities. Central to this approach is a commitment to a view of learning that emphasises the role of the context in learning and points to the importance of learning in authentic situations.

While digital inclusion programs tend to focus more specifically on teaching people how to use computers and the internet, the approach presented in this paper takes a different perspective. According to this approach, to be effective learning for digital inclusion has to be situated in the social context of the learners and be based on authentic activities of project development that address issues of these social contexts. This makes it possible to connect digital inclusion to social inclusion in profitable ways, improving the possibilities of underdeveloped communities obtaining social inclusion through digital inclusion, and creating self-sustainable forms of social development. The approach is being applied in a program of digital and social inclusion that is being carried out in a rural community of agricultural families in the Brazilian Northwest.
\end{abstract}

Keywords: digital inclusion, authentic situations, social context, learning portals. 


\section{Introduction}

The aim of this paper is to present an approach to digital inclusion which situates learning for digital inclusion in the social context of communities. Central to this approach is a commitment to a view of learning that emphasises the role of the context in learning and points to the importance of learning in authentic situations. While digital inclusion programs tend to focus more specifically on teaching people how to use computers and the internet, the approach presented in this paper takes a different perspective. According to this approach, to be effective learning for digital inclusion has to be situated in the social context of the learners and be based on authentic activities of project development that address issues of these social contexts. This makes it possible to connect digital inclusion to social inclusion in profitable ways, improving the possibilities of underdeveloped communities obtaining social inclusion through digital inclusion, and creating self-sustainable forms of social development.

The approach includes three phases. In the first phase, the focus is on allowing children to address their social context through digital inclusion activities. To do so, the children of the community are involved in the development of small projects in which they can learn an internet language and use that language to express issues of their social context. In this phase, learning for digital inclusion is based on the development of prototypes of learning portals in which the students learn HTML and use that language to create content for learning portals on subjects that are relevant to their community. These projects with learning portals provide the authentic activities that make learning for digital inclusion meaningful for the children.

The objective of the second phase is to promote the digital inclusion of the teachers of the rural school where the project is being developed, with a focus on allowing them to address the school context in digital inclusion activities. This involves the development of a digital inclusion program for the teachers that is similar to the one developed for the students, but with a different focus. In this program the teachers learn an internet language (also HTML) and use that language to develop prototypes of learning portals based on content that they create on subjects that they teach at the school. The first and second phase will run in parallel.

In the third phase of the approach, the aim is to extend the work done in the two previous phases to the whole community, involving them in creating a free learning portal on issues of their social context to be used to promote and facilitate social inclusion, with a view of preparing them for independent learning based on the internet. The prototypes of learning portals developed by the students and the teachers in the first and second phases of the digital inclusion program will then evolve to become a free learning portal on issues that are relevant to the development of the whole community.

In the next sections we describe these three phases of the program of digital and social inclusion that we are developing in a rural community of agricultural families in the Brazilian Northwest. The aim is to situate learning for digital inclusion in the social 
context of these communities in order to enable the development of social inclusion from digital inclusion.

\section{Authentic Situations for Digital Inclusion}

According to contemporary theories of learning, the social and physical context of the situation in which learning takes place is an integral part of what is learned in the situation, and is what makes learning in the situation meaningful. These theories also emphasize the central role of constructive activity in meaningful learning. In addition, according to a situated learning perspective, learning is a matter of constructing an identity and of participating in a community of practice, so that learners can develop the capacity to act as members of the community in which this knowledge is situated and meaningful (Brown, Collins and Duguid, 1989; Lave and Wenger, 1991).

Therefore, in order to provide a productive learning environment, the context of the learning activities, in addition to the content and dynamics of these activities, should be an issue to be carefully considered in the design of the learning environment. For example, studies that compared the conditions in which learning develops in school with those that are present when learning happens out of school have pointed out to the importance of learning in authentic situations (Resnick, 1987). Authentic situations are situations that take into consideration the activities that people develop in the real life contexts in which the knowledge learned is applied, so that learners can understand the generative power of the items of knowledge that they are learning (Greeno, 1989; Brown, Collins and Duguid, 1989).

Addressing these views in our work to support learning for digital and social inclusion we have developed an approach in which learning for digital inclusion occurs in authentic situations. The two main characteristics of the approach that support this view are the construction of learning portals and the use of audiovisuals. The construction by learners and teachers of learning portals on subjects that are relevant to their social and school contexts, using visual representations of these contexts, enables them to deal with real issues of these contexts in project-based constructive activities that will provide the authentic learning situations for digital inclusion.

\section{Addressing the Social and the School Contexts}

In the first phase of our approach to digital inclusion we involve the students in the development of information technology projects in which they can learn information technology languages and become able to express themselves in these languages. In the program that we are developing in the Brazilian northwestern region, the language that they are learning is HTML and the projects in which the students will work to learn the language include the development of prototypes of learning portals in a subject that is relevant to the social context in which the students live.

The students come from poor rural communities in a region that has a potential for the development of an agriculture that can be used for the production of bio-diesel, which is viewed as a way of generating income and promoting social inclusion to these communities. A program of training farmers to cultivate plants that can be used to 
produce oil is being developed in the region as part of a government plan to increase the production of renewable sources of energy by small farms in order to provide social inclusion. This is the social context of the community in which our program of digital inclusion is being applied.

Therefore, the social context of the digital inclusion students is characterized by the following:

- An agricultural community that is changing to a new kind of agriculture and needs to learn new agricultural techniques.

- An agricultural community that needs to participate in a new kind of business to sell the product of their farms for the production of bio-diesel.

In this context, the prototypes of learning portals that the learners will be developing to learn HTML will be based on the training that will be given to the farmers in the new agricultural techniques. To be used as part of the content of these learning portals, we will produce audiovisuals of the training program during its development, with the participation of the students.

This will provide authentic situations (the training of farmers of the community in the new agricultural techniques) and constructive activities (the building of real learning portals in a real context) for learning.

The whole program of learning for digital inclusion will take one year to be applied in a rural community of the northwestern region and the plan includes a second year in which another more distant rural community will be reached. The program includes an introductory course in which the elements of the HTML language will be introduced to the students, and practical activities in which the students will work in the development of the projects of learning portals.

A summary of the activities that are being developed in the program of learning for digital inclusion, with regard to the development of the projects of learning portals, is presented below.

1) Teaching HTML to the students in an introductory course based on lectures and exercises addressing social subjects.

2) Obtaining information for the development of the learning portals, which will involve the students and the farmers working together, as well as the agriculture instructors.

3) Producing audiovisuals about the subject, integrated with the training program.

4) Design of the prototypes of learning portals by the students, using the audiovisuals produced.

5) Implementation of the prototypes of learning portals by the students, using the HTML language. 
6) Exposing the prototypes of learning portals to use by people to obtain feedback.

In the second phase of our approach to digital inclusion we involve the teachers in the development of information technology projects in which they can learn information technology languages and become able to express themselves in these languages. In the program that we are developing in the Brazilian northwestern region, the language they are learning is also HTML and the projects in which the teachers will work to learn the language include the development of prototypes of learning portals on subjects that are relevant to the school context in which the teachers work.

In this phase, the focus of the learning portals will be the subjects that are taught in the school. The teachers of the rural school where the project is being developed are already working on the development of learning materials that are contextualized to the region. This material will be the basis for the creation of content for the learning portals.

The activities to be developed in this second phase include the following:

1) Teaching HTML to the teachers in an introductory course based on lectures and exercises addressing school subjects.

2) Obtaining information for the development of the learning portals, which will involve the teachers working on the learning material that they use to teach at the school.

3) Producing audiovisuals about the subjects that are part of the learning material.

4) Design of the prototypes of learning portals by the teachers, using the audiovisuals produced.

5) Implementation of the prototypes of learning portals by the teachers, using the HTML language.

6) Exposing the prototypes of learning portals to use by the students to obtain feedback.

The rural school where the project is being developed has just received a link to the internet, and the teachers have never used it as yet. The digital inclusion program applied to the teachers will help them not only to use the internet but also to create content for the internet to support their classes.

\section{Building Learning Portals for the Social Inclusion of Communities}

One of the main aspects of our approach to digital inclusion in social contexts is that in order to learn an information technology language (such as HTML), students and teachers develop information technology projects in which they use that language to address real issues of their social and school contexts. These projects provide the authentic activities that make their learning for digital inclusion meaningful.

However, the more central aspect of the approach lies not in the fact that learning is based on authentic project development activities, but in the fact that the projects that are developed by students and teachers in their learning processes are projects of 
learning portals. This allows us to address two issues that are important for pursuing the next phase of the digital inclusion program, which points to independent learning.

First, in the process of creating the content for their learning portals the students become authors of the knowledge that needs to be learned by the people of their community to improve their lives (the new agricultural techniques), and the teachers become authors of the knowledge that needs to be learned by the students at school. In this process, they gain an understanding of the issue of knowledge representation in learning portals that is also grounded in an authentic context and, therefore, is more comprehensible to them.

Second, the use of audiovisual media to represent part of the knowledge that constitutes the content of the learning portals allows the learners to address the tacit aspects of the knowledge as well as its social, cultural and physical dimensions in a more effective way.

Therefore, at the end of this process, students and teachers have not only acquired literacy in ways of expressing information to the internet but also acquired literacy in ways of learning through the internet, as they have become prepared to understand as well as to create and use learning portals. This is a very valuable literacy because it is a literacy that gives them more autonomy to learn from the internet. It is also a literacy in learning to learn, which brings them further empowerment.

The third phase of the digital inclusion program follows from this point and is based on the creation and use of free learning portals to support social inclusion. The prototypes of learning portals developed by the students in the first phase of the digital inclusion program will now evolve to become a free learning portal on issues of bio-diesel production.

This may have several further consequences for the community. First, the learning portals can continue to be developed and become a future source of information to farmers, providing for their digital inclusion too, turning into an information technology artifact that is relevant to the farmers' community. Second, the learning portals in its continuing development can be a way of connecting the farmers to other communities in the bio-diesel production chain, improving their connectedness and digital inclusion in useful ways.

Furthermore, the work of creating a learning portal with the participation of the community, using the prototypes of learning portals developed by the students in their digital inclusion projects, is an important step to insert the community into the information society.

Therefore, in order to support the third phase of the digital inclusion program we need to develop a framework for the creation and use of free learning portals, which is discussed next. 


\subsection{Designing Learning Situations}

The main issue addressed in the design of free learning portals is the learner's autonomy to learn. Free learning portals should provide a flexible and adaptive support to the learner, facilitating independent learning and making it possible for the learners to learn according to their interests and needs.

In addition, in our approach to digital inclusion, learning is situated in social contexts. Therefore, an issue to be addressed in the design of a free learning portal for digital and social inclusion is the role of the context in learning. Taking this issue into consideration in the design of a learning portal leads to the need to represent the contexts of learning as central components of learning interactions in the portal, and of situating learning activities in these contexts.

To represent the context of learning in learning environments, we have developed an approach that is based on a model of situations (Akhras, 2005). Designing the learning portal according to this model means organizing the knowledge to be learned in the portal in terms of situations, rather then solely in terms of information to be accessed. This leads to a situation-oriented approach to the design of learning portals in which the portal pages are created with a focus on the content and dynamics of learning situations. The content may include sources of information as well as other entities, and the dynamics may include ways of accessing information as well as ways of developing other kinds of interaction with the entities of the situation.

Taking a situation-oriented approach to the design of learning portals involves consideration of the following general principles (Brown, Collins and Duguid, 1989; Bednar, Cunningham, Duffy and Perry, 1992):

- $\quad$ Learning situations have to be authentic, portraying activities of the real life contexts in which the knowledge learned is applied.

- $\quad$ Learning situations will embody the social and cultural aspects related to these contexts, reflected, for example, in the practices of members of the community, their common views, and their tools.

These aspects of learning situations may appear in the portal in the form of images, sound, text, graphics or computational simulations.

To provide ways for learners to develop meaningful and productive learning interactions, the opportunities for activity in learning situations may include the following:

- $\quad$ Action events (including ways of accessing, using or creating information, or other entities of a domain, in the context provided by a situation).

- $\quad$ Communication events (including ways of communicating with other learners or living entities in the context provided by a situation). 
Through these kinds of activity, learners interact in a situation taking the physical or conceptual entities of the situation as objects of their actions and producing new or transformed entities.

\subsection{Supporting Independent Learning}

In order to facilitate independent learning a free learning portal must be adaptive to the learner. This leads to the need for monitoring learning situations.

Monitoring learning situations allows us to collect meaningful data about the interactions that occur in these situations. The data collected will be analysed to look for desirable characteristics in the learning process developed. This analysis will be used to guide the adaptation of the learning portal, and the adaptation is in terms of providing access to the user, to those learning situations that will be more helpful to the user in terms of facilitating the development of the desirable characteristics in the next steps of his or her learning process.

Therefore, these two concerns - situation-oriented and adaptive - are the main requirements of free learning portals for digital and social inclusion. On that basis we have produced a general design of a free learning portal to be used in our work with the community, in the third phase of the digital and social inclusion program. This general design, which is briefly described below, will support the work to extend the prototypes of learning portals to create a free learning portal.

A central aspect of a free learning portal is the adaptation of the content (the learning situations) to the needs of the users, in the course of the learning process. This requires the design of a system intelligence that can provide the kind of adaptation needed (Akhras and Self, 2000).

The learning portal that we have designed on the basis of the issues discussed above consists of a set of web pages which characterise learning situations. Each situation contains audiovisual content of the knowledge to be learned and its context, and means of interacting with this content. The access to these pages is based on a learning strategy which takes into consideration the learning goals, the user's previous course of interaction in the portal situations, and the knowledge acquired by the user in these situations. The portal also offers the possibility of choice of situations to be accessed by the user. On the basis of this, the portal will operate as follows.

1) At each moment a set of situations (web pages) which attend the user needs in that particular moment of his of her learning process is presented to the user for a choice of a situation to access next.

2) The choice of the situation to access next is made by the user or by the portal (by the adaptation system) according to the moment of the learning process or by user choice.

3) Accessing a web page makes the user enter the learning situation characterised by that page allowing him or her to interact with the content of that situation. 
4) All interactions occur in a situation that is relevant to obtaining the observations needed to adapt the portal to the user's needs and are recorded by the portal (by the adaptation system).

5) On the basis of the recorded data of the interactions which occurred in the web page, the portal captures aspects of the user performance in the learning situation, such as the knowledge learned or failed to learn in the interactions with the situation, determining the user's state of knowledge and the course of her or his learning process. This will provide information to the adaptation system of the portal.

6) From the user's state of knowledge, the learning goal, the learning situations available (with their content and dynamics), the previous occurrences of the learning process, and on the basis of a defined learning strategy, the adaptation system of the portal determines the learning situations that are more beneficial to the user, at that moment of his or her learning process. This corresponds to the adaptation of the portal to the user's needs.

7) As a result of this adaptation a set of situations, and corresponding web pages, are provided which can attend the current needs of the user, and a new cycle starts, from the step (1) above, until the intended learning process has been completed and the learning goals have been achieved.

In the first phase of the digital inclusion program, students from a rural community are creating prototypes of learning portals on a subject that is relevant to the social inclusion of their community. In the second phase, which is running in parallel with the first phase, the teachers of the rural school where the project is being developed are learning an internet language to create content for learning portals on subjects of their teaching that are relevant to the school context. In the third phase of the digital inclusion program, these prototypes of learning portals developed by the students will evolve to become a free learning portal on the subject of agricultural techniques for the production of bio-diesel, to be used by the communities involved in the bio-diesel production program.

The work to move from these prototypes, which were developed for the purpose of learning for digital inclusion, to a complete learning portal to be made available to the communities for free learning, is a work of design that should involve the users. After the first and second phases of the digital inclusion program, in which students and teachers acquired literacy on issues of learning portals, they are now able to participate in the design of a learning portal that can be more attuned to the issues and views of their community.

\section{Conclusion}

We have described an approach to learning for digital inclusion which takes into consideration the social and school context of students and teachers of a rural community and is based on authentic activities. In doing so, the digital inclusion program is integrated to the social context of the community where the program is 
applied with a view of facilitating the development of social inclusion from digital inclusion.

The approach is being applied in a program of digital and social inclusion that is being carried out in a rural community of agricultural families in the Brazilian Northwest, and involves three phases. In the first and second phases, learning for digital inclusion is based on the development of prototypes of learning portals in which students and teachers learn the HTML language and use that language to create prototypes of learning portals on subjects that are relevant to their contexts.

In the third phase, a more advanced approach is explored with the aim of working with the members of the community to prepare them for independent learning and also to involve them in creating a free learning portal on issues of their social context (biodiesel production) to be used to promote and facilitate social inclusion.

The main characteristics of the approach, are:

The construction of learning portals - the construction by learners and teachers of learning portals on subjects of their social and school contexts using visual representations of these contexts, allowing students and teachers to deal with issues of their social and school contexts in project-based constructive activities that will be part of their learning for digital inclusion.

The use of audiovisuals - the production and use of audiovisuals on subjects of the social and school contexts of students and teachers as a way of providing visual representations of aspects of these contexts to be used in the projects that students and teachers will develop as part of the digital inclusion program.

The focus on learning to learn - the focus on learning to learn, through the development of learning portals, will allow students and teachers to go from literacy in digital technologies to literacy in learning from digital technologies.

The application of a community-centred design approach - the design of free learning portals as an activity that will involve the community which will enrich the digital inclusion process and ground the design of the free learning portal in an authentic context.

Finally, the main purpose of the approach described in this paper is to situate learning for digital inclusion in the social context of communities, in order to create the conditions for the members of the community to become independent learners, so that they can provide for their own further digital and social inclusion.

\section{Acknowledgements}

The work reported in this paper is being sponsored by the National Council of Scientific and Technological Development (CNPq) in cooperation with the Secretary of the Agricultural Family (SAF) of the Ministry of Agricultural Development (MDA) of Brazil. 


\section{References}

Akhras, F. N. (2005). Modelling the context of learning interactions in intelligent learning environments. Proceedings of the 5th International and Interdisciplinary Conference on Modeling and Using Context (CONTEXT'05), Paris, France. SpringerVerlag, 1-14.

Akhras, F. N. \& Self, J. A. (2000). System intelligence in constructivist learning. International Journal of Artificial Intelligence in Education, 11(4), 344-376.

Bednar, A. K., Cunningham, D., Duffy, T. M. \& Perry, J. D. (1992). Theory into practice: how do we link? In Duffy, T. M. and Jonassen, D. H. (Eds.), Constructivism and the Technology of Instruction: a Conversation (pp. 17-34). Hillsdale, NJ: Lawrence Erlbaum.

Brown, J. S., Collins, A. \& Duguid, P. (1989). Situated cognition and the culture of learning. Educational Researcher, 18(1), 32-42.

Greeno, J. G. (1989). A perspective on thinking. American Psychologist, 44(2), 134141.

Lave, J., \& Wenger, E. (1991). Situated learning: Legitimate pheripheral participation. Cambridge. England: Cambridge University Press.

Resnick, L. B. (1987). Learning in school and out. Educational Researcher, 16(9), 1320. 